\title{
Catalytic Mechanism Comparison Between 1,2-Dichloroethane-Acetylene Exchange Reaction and Acetylene Hydrochlorination Reaction for Vinyl Chloride Production: DFT Calculations and Experiments
}

\author{
Hao Xu *, Baochang Man and Guohua Luo * \\ Beijing Key Laboratory of Green Chemical Reaction Engineering and Technology, Department of Chemical \\ Engineering, Tsinghua University, Beijing 100084, China; mbcthu@163.com \\ * Correspondence: xh14@mails.tsinghua.edu.cn (H.X.); luoguoh@tsinghua.edu.cn (G.L.); \\ Tel.: +86-188-1026-5786 (H.X.); +86-10-62788994 (G.L.)
}

Received: 17 January 2020; Accepted: 4 February 2020; Published: 8 February 2020

\begin{abstract}
The catalytic mechanism and activation energies of metal chlorides $\mathrm{RuCl}_{3}, \mathrm{AuCl}_{3}$, and $\mathrm{BaCl}_{2}$ for 1,2-dichloroethane (DCE)-acetylene exchange reaction were studied with a combination of density functional theory (DFT) calculations and experiments. Two reported reaction pathways were discussed and acetylene-DCE complex pathway was supported through adsorption energy analysis. The formation of the second vinyl chloride monomer (VCM) was proven to be the rate-determining step, according to energy profile analysis. Activity sequence of $\mathrm{BaCl}_{2}>\mathrm{RuCl}_{3}>\mathrm{AuCl}_{3}$ was predicted and experimentally verified. Furthermore, reversed activity sequences of this reaction and commercialized acetylene hydrochlorination reaction were explained: the adsorption abilities of reactants are important for the former reaction, but chlorine transfer is important for the latter.
\end{abstract}

Keywords: DFT study; metal chlorides; DCE-acetylene exchange reaction; acetylene hydrochlorination; catalytic mechanism

\section{Introduction}

Poly vinyl chloride (PVC) is one of the most versatile plastics synthesized by radical polymerization of vinyl chloride monomer (VCM). China is the biggest PVC production country in the world, and over $80 \%$ of VCM is produced through the acetylene method (also called calcium carbide method) $[1,2]$. Acetylene hydrochlorination is the core reaction in the process [3,4]:

$$
\mathrm{CH} \equiv \mathrm{CH}+\mathrm{HCl} \stackrel{\text { Catalyst }}{\rightarrow} \mathrm{CH}_{2}=\mathrm{CHCl} \Delta H=-124.8 \mathrm{~kJ} \cdot \mathrm{mol}^{-1}
$$

Mercury chloride that is loaded on carbon is the traditional industrial catalyst for this reaction, while the high toxicity and volatility can be a great threat to human and environment [5]. A worldwide Minamata Convention came into effect in 2017, which regulates specific policies on mercury inhibition [6]. New reaction routes and non-mercury catalysts for VCM production is urgently needed for future green PVC industry.

1,2-dichloroethane (DCE) is an important intermediate for organic synthesis, which is also the by-product of the coal-based industrial VCM process. However, its use is avoided in daily life and a further conversion is preferred due to toxicity and carcinogenicity. Therefore, the exchange reaction between DCE and acetylene to produce VCM is attractive in the academic field. This new process has 
been firstly reported by Jiang and Zhong et al. [7], and is therefore also called the "Jiang-Zhong VCM process". The core reaction in this new process can be written as [4]:

$$
\mathrm{CH} \equiv \mathrm{CH}+\mathrm{ClCH}_{2} \mathrm{CH}_{2} \mathrm{Cl} \stackrel{\text { Catalyst }}{\rightarrow} 2 \mathrm{CH}_{2}=\mathrm{CHCl} \Delta H=-29.7 \mathrm{~kJ} \cdot \mathrm{mol}^{-1}
$$

When comparing with traditional acetylene hydrochlorination process, the newly reported Jiang-Zhong VCM process has outstanding advantages: (1) higher yield of main product due to reuse of byproduct DCE; (2) lower heat effect due to good balance of endothermic (DCE decomposition) and exothermic (acetylene hydrochlorination) reactions; (3) avoidance of corrosive $\mathrm{HCl}$; and, (4) halved acetylene consumption and corresponding waste generated from coal-based acetylene production. The new route can be regarded as a combination of the coal and petroleum chemical industry and it opens up new possibilities for greener VCM production. However, the published results on this new route are notably limited and an instructive understanding is of great importance.

Density functional theory (DFT) is becoming a very useful tool for computational material science and chemistry [8]. However, to the best of our knowledge, no DFT study has been reported for the new Jiang-Zhong VCM process, and the experimental exploration is also in the early stage. It is highly useful for guiding the rational development of novel DCE-acetylene exchange catalysts with the assistance of computational chemistry.

In this work, the catalytic reaction mechanisms of $\mathrm{RuCl}_{3}, \mathrm{AuCl}_{3}$, and $\mathrm{BaCl}_{2}$ for DCE-acetylene exchange reaction were studied in detail by DFT calculation. The experiments were further carried out and a high consistency between DFT calculations and experimental results was achieved. When comparing with the traditional acetylene hydrochlorination reaction, the reversed activity sequence was anticipated, which was explained by the differences in mechanisms. The work provided guidance for the deep understanding and screening methodology of catalysts for DCE-acetylene exchange reaction, which can accelerate the development of this green and highly efficient route for VCM production.

\section{Results and Discussion}

\subsection{Selection and Structure of Metal Chlorides}

As for DCE-acetylene exchange reaction, Jiang et al. first reported the activity of $\mathrm{BaCl}_{2}$ in 2013 [7]. Future work suggested that the $\mathrm{BaCl}_{2}$ catalyst demonstrates $70 \%$ acetylene conversion and $98 \%$ selectivity to VCM at the temperature of $200-230{ }^{\circ} \mathrm{C}$ and acetylene GHSV (gas hourly space velocity) of $24 \mathrm{~h}^{-1}$ [9]. In 2016, Zhao et al. reported a Ru-based catalyst for the reaction, which showed $15 \%$ acetylene conversion and $99 \%$ VCM selectivity at $250{ }^{\circ} \mathrm{C}$ and $57 \mathrm{~h}^{-1}$ acetylene GHSV [10]. Besides, $\mathrm{AuCl}_{3}$ also demonstrated unique adsorption and activation ability of acetylene, which is also advantageous for this reaction [11]. Therefore, these three metal chlorides were adopted as initial exploration in this work.

Metal chlorides were considered as the main active sites for this reaction, due to the fact that a reduced catalyst with metal clusters/particles demonstrates significantly reduced activity (Figure S8). A reasonable simplification was applied and the simplest structures of metal chlorides were selected during calculation. First, metal chlorides in its original form were optimized and Figure S1 shows the results. It can be concluded that $\mathrm{RuCl}_{3}$ and $\mathrm{BaCl}_{2}$ are non-polar molecules (zero dipole moment) with regular plane triangular and linear structure, respectively, while $\mathrm{AuCl}_{3}$ demonstrates an isosceles triangular structure with a dipole moment of 0.0671 Debye. Other references also confirmed these specific structures [12-16].

\subsection{Possible Reaction Mechanisms}

In this work, two possible reaction pathways were taken into consideration, which were also discussed in previous work $[17,18]$. Figure 1 shows the illustration of two pathways, in which the catalyst (Cat) is temporarily represented by a dummy atom for clarity. The first pathway is defined as 
the DCE decomposition pathway. In this pathway, DCE first gets adsorbed on the catalytic surface and releases one VCM molecule, leaving one adsorbed $\mathrm{HCl}$ molecule. Afterwards, the catalyst further adsorbs one $\mathrm{C}_{2} \mathrm{H}_{2}$ molecule and another VCM molecule is formed. Finally, the catalyst returns to its original form after the desorption of the second VCM molecule. The second pathway is defined as the acetylene-DCE complex pathway. In the first step, $\mathrm{C}_{2} \mathrm{H}_{2}$ rather than DCE gets adsorbed. Next, one DCE molecule gets adsorbed, subsequently forming an acetylene-DCE complex. Subsequently, one VCM molecule gets released and the rest $\mathrm{HCl}$ and $\mathrm{C}_{2} \mathrm{H}_{2}$ molecules form another VCM. Finally, the second VCM gets desorbed and the catalyst returns to its original form. It can be seen that the most significant difference between the two pathways is the adsorption sequence in the first step: DCE gets adsorbed prior to $\mathrm{C}_{2} \mathrm{H}_{2}$ in the first pathway and $\mathrm{C}_{2} \mathrm{H}_{2}$ gets adsorbed prior to DCE in the second pathway. Therefore, the adsorption ability of $\mathrm{C}_{2} \mathrm{H}_{2}$ and DCE becomes a crucial criterion for the priority of two pathways.

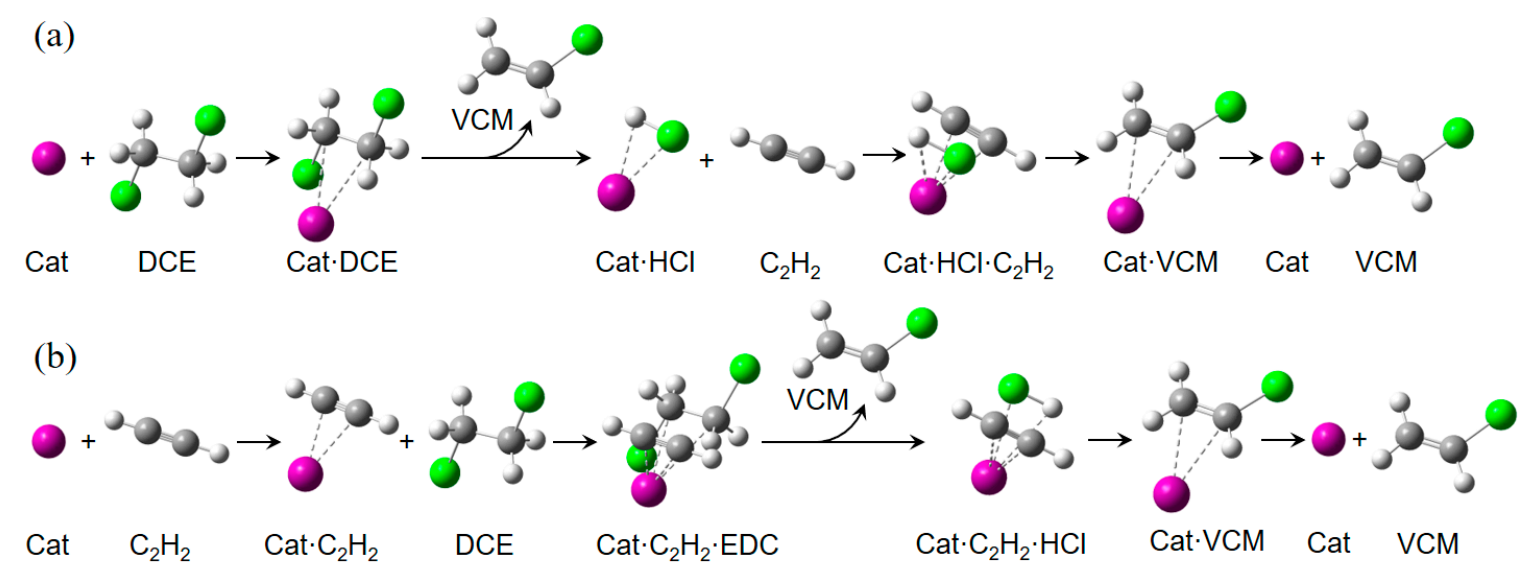

Figure 1. Illustration of two possible reaction pathways for 1,2-dichloroethane (DCE)-acetylene exchange reaction. (a) DCE decomposition pathway; (b) acetylene-DCE complex pathway.

\subsection{Adsorption Energy on Metal Chlorides}

The adsorption energy calculation of the important species in this reaction was carried out in the optimized metal chloride systems. Figure S2 gives the structures and Table 1 lists the corresponding adsorption energies. Besides, Table $\mathrm{S} 1$ lists important structure parameters of each species. It should be noted that the adsorption of $\mathrm{C}_{2} \mathrm{H}_{2}$ is stronger than DCE for all catalysts, which indicates that $\mathrm{C}_{2} \mathrm{H}_{2}$ tends to be adsorbed on the catalytic surface prior to DCE. Therefore, the second pathway (acetylene-DCE complex pathway) in Figure $1 \mathrm{~b}$ is supported, as discussed in the previous part. Furthermore, the adsorption of VCM is also stronger than $\mathrm{HCl}$ for all cases, which indicates that the adsorbed $\mathrm{HCl}$ species tends to desorb prior to VCM. This conclusion is another evidence against the first pathway (DCE decomposition pathway): VCM gets desorbed prior to $\mathrm{HCl}$ in this pathway, contradicting with calculated adsorption energies. However, no VCM gets desorbed prior to $\mathrm{HCl}$ or $\mathrm{C}_{2} \mathrm{H}_{2}$, respectively (rather than the co-adsorbed species), in the second pathway, and it is thus proved to be more reasonable.

Table 1. Adsorption energies of DCE, $\mathrm{C}_{2} \mathrm{H}_{2}, \mathrm{HCl}$, and vinyl chloride monomer (VCM) on the catalytic surfaces. Unit: $\mathrm{kJ} \mathrm{mol}^{-1}$.

\begin{tabular}{ccccc}
\hline Catalyst & $E_{\text {ads }}(\mathbf{D C E})$ & $E_{\text {ads }}\left(\mathbf{C}_{\mathbf{2}} \mathbf{H}_{2}\right)$ & $E_{\text {ads }}(\mathbf{H C l})$ & $E_{\text {ads }}(\mathbf{V C M})$ \\
\hline $\mathrm{RuCl}_{3}$ & -22.6 & -149.3 & 36.0 & -193.4 \\
$\mathrm{AuCl}_{3}$ & -51.4 & -106.0 & 39.1 & -179.0 \\
$\mathrm{BaCl}_{2}$ & -122.9 & -161.9 & -73.9 & -215.0 \\
\hline
\end{tabular}


According to Table $1, \mathrm{BaCl}_{2}$ demonstrates the strongest adsorption ability for all four species. Especially for $\mathrm{HCl}, \mathrm{BaCl}_{2}$ leads to moderate adsorption energy, while the adsorption of $\mathrm{HCl}$ is not favorable on $\mathrm{RuCl}_{3}$ and $\mathrm{AuCl}_{3}$ (positive adsorption energy). This tendency can be explained by the flexibility of $\mathrm{BaCl}_{2}$, since the linear structure can be easily deformed to suit for adsorbates, as shown in Figure S2. The conclusion is also proved by the structure parameters listed in Table S1, since the bond lengths of adsorbed species increase the most on $\mathrm{BaCl}_{2}$ surface. The strong adsorption of reactant is a great advantage of $\mathrm{BaCl}_{2}$ to be the suitable catalyst for DCE-acetylene exchange reaction.

\subsection{Energy Profiles}

The energy profiles for two reaction pathways were calculated. Tables S2 and S3 list the original energy values. Figures 2 and 3 shows the energy profiles and corresponding structures. It can be seen that, in both pathways, the energies of transition states (TS1 and TS2 in Figures 2 and 3) have the sequence of $\mathrm{BaCl}_{2}<\mathrm{RuCl}_{3}<\mathrm{AuCl}_{3}$. A sequence of $\mathrm{BaCl}_{2}>\mathrm{RuCl}_{3}>\mathrm{AuCl}_{3}$ can be expected for assisting the reaction since lower energy leads to more stable reaction intermediates. This conclusion is consistent with the discussion in the previous part and published experimental studies, in which $\mathrm{BaCl}_{2}$ gives the highest activity [9,10]. It is interesting that noble metals, such as $\mathrm{Au}$ and $\mathrm{Ru}$, do not show advantages for this reaction, despite their prominent performance for acetylene hydrochlorination reaction (activity sequence of $\mathrm{AuCl}_{3}>\mathrm{RuCl}_{3}>\mathrm{BaCl}_{2}$ has been reported, Figure S3) [19-22]. Section 2.7 provides the explanation of reversed activity sequences for the two reactions.

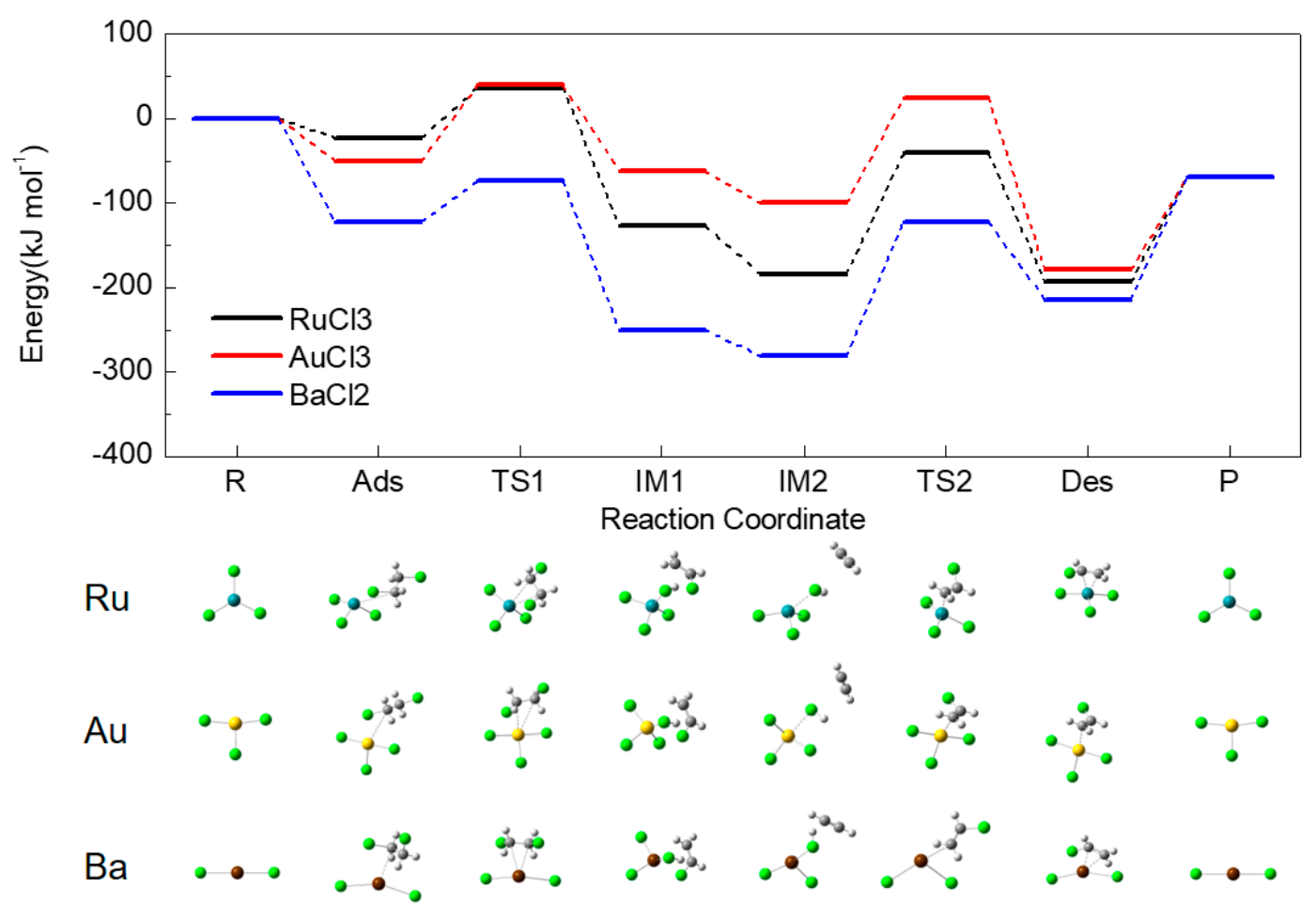

Figure 2. Energy profiles and corresponding structures of species for DCE-exchange reaction: DCE decomposition pathway. Free molecules of DCE, $\mathrm{C}_{2} \mathrm{H}_{2}, \mathrm{HCl}$, and VCM are omitted for clarity. 


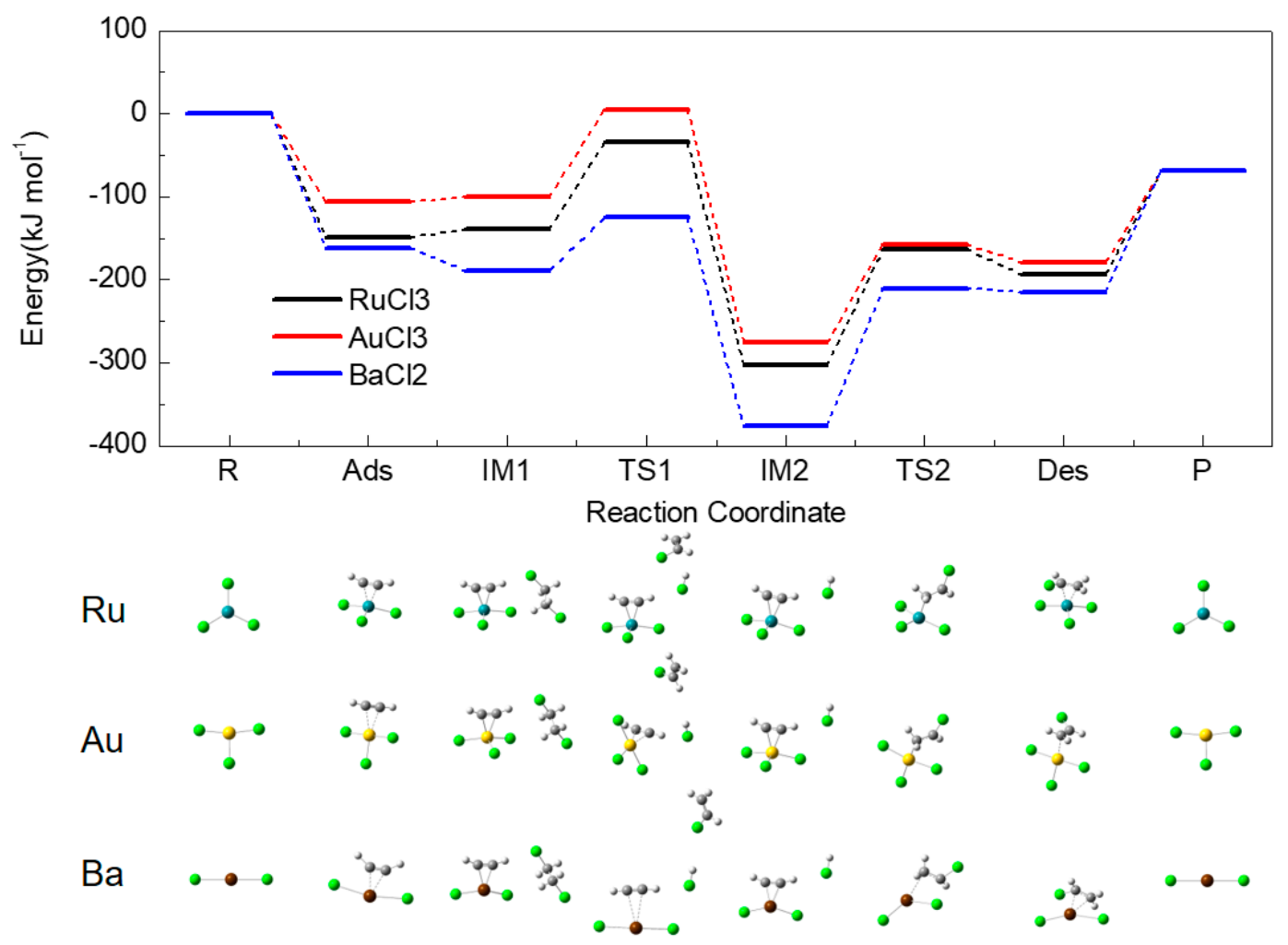

Figure 3. Energy profiles and corresponding structures of species for DCE-exchange reaction: acetylene-DCE complex pathway. Free molecules of DCE, $\mathrm{C}_{2} \mathrm{H}_{2}, \mathrm{HCl}$, and $\mathrm{VCM}$ are omitted for clarity.

\subsection{Activation Energy}

Table 2 lists the energy barriers of metal chloride systems during the two reaction pathways. $E_{\mathrm{a} 1}$ refers to $E_{\mathrm{TS} 1}-E_{\mathrm{Ads}}$ in DCE-decomposition pathway and $E_{\mathrm{TS} 1}-E_{\mathrm{IM} 1}$ in acetylene-DCE complex pathway, while $E_{\mathrm{a} 2}$ denotes $E_{\mathrm{TS} 2}-E_{\mathrm{IM} 2}$ in both pathways. It can be seen that $E_{\mathrm{a} 2}>E_{\mathrm{a} 1}$ in all cases, indicating the formation of the second VCM is the rate-determining step for all catalysts in both pathways. The activation energy $\Delta G_{\mathrm{RDS}}$ (at $473.15 \mathrm{~K}$ ) was calculated as the Gibbs free energy difference of the rate-determining step. It can be seen that the activation energy in two pathways are similar for all of the metal chloride catalysts, which can be explained by the similarity of the last step in both reaction pathways. The corresponding activation energies of $\mathrm{RuCl}_{3}, \mathrm{AuCl}_{3}$, and $\mathrm{BaCl}_{2}$ are adopted to be 189.1, 141.4 , and $167.3 \mathrm{~kJ} \mathrm{~mol}^{-1}$, respectively, since the second pathway is proved to be favorable. These values can be further compared with experimental activation energies $\left(E_{\mathrm{a}}(\exp )\right)$, which will be shown in Section 2.6.

Table 2. Activation energies for two reaction pathways at $473.15 \mathrm{~K}$. Experimental values and the relative errors are also listed. Energy unit: $\mathrm{kJ} \mathrm{mol}^{-1}$.

\begin{tabular}{ccccccccc}
\hline \multirow{2}{*}{ Catalyst } & \multicolumn{3}{c}{ DCE Decomposition } & \multicolumn{3}{c}{ Acetylene-DCE Complex } & \multirow{2}{*}{$E_{\mathbf{a}}(\exp )$} & \multirow{2}{*}{ Error (\%) } \\
\cline { 2 - 6 } & $\boldsymbol{E}_{\mathbf{a} 1}$ & $\boldsymbol{E}_{\mathbf{a} 2}$ & $\boldsymbol{\Delta} \boldsymbol{G}_{\mathbf{R D S}}$ & $\boldsymbol{E}_{\mathbf{a} 1}$ & $\boldsymbol{E}_{\mathbf{a} 2}$ & $\boldsymbol{\Delta} \boldsymbol{G}_{\mathbf{R D S}}$ & & \\
\hline $\mathrm{RuCl}_{3}$ & 58.6 & 142.9 & 185.5 & 105.4 & 139.6 & 189.1 & 152.8 & -19.2 \\
$\mathrm{AuCl}_{3}$ & 90.6 & 125.5 & 128.0 & 106.6 & 118.5 & 141.4 & 134.2 & -5.1 \\
$\mathrm{BaCl}_{2}$ & 49.0 & 159.7 & 176.6 & 64.8 & 165.8 & 167.3 & 141.3 & -15.5 \\
\hline
\end{tabular}

\subsection{Comparison with Experimental Data}

Experiments were carried out to further verify the predictions based on DFT calculations. All metal chlorides were loaded on activated carbon support with a 10\% weight content through impregnation 
in order to facilitate the dispersion of active metal chlorides and produce comparable results. The support activated carbon was proved to show extremely limited activity in the DCE-acetylene exchange reaction, as shown in Figure S8. Detailed evaluation process (Figure S4) and kinetic study can be found in the Supplementary Information (Figures S5-S7). Figure 4 shows the logarithm of reaction rate constant $K$ vs the reciprocal of reaction temperature $(1 / T)$ results.
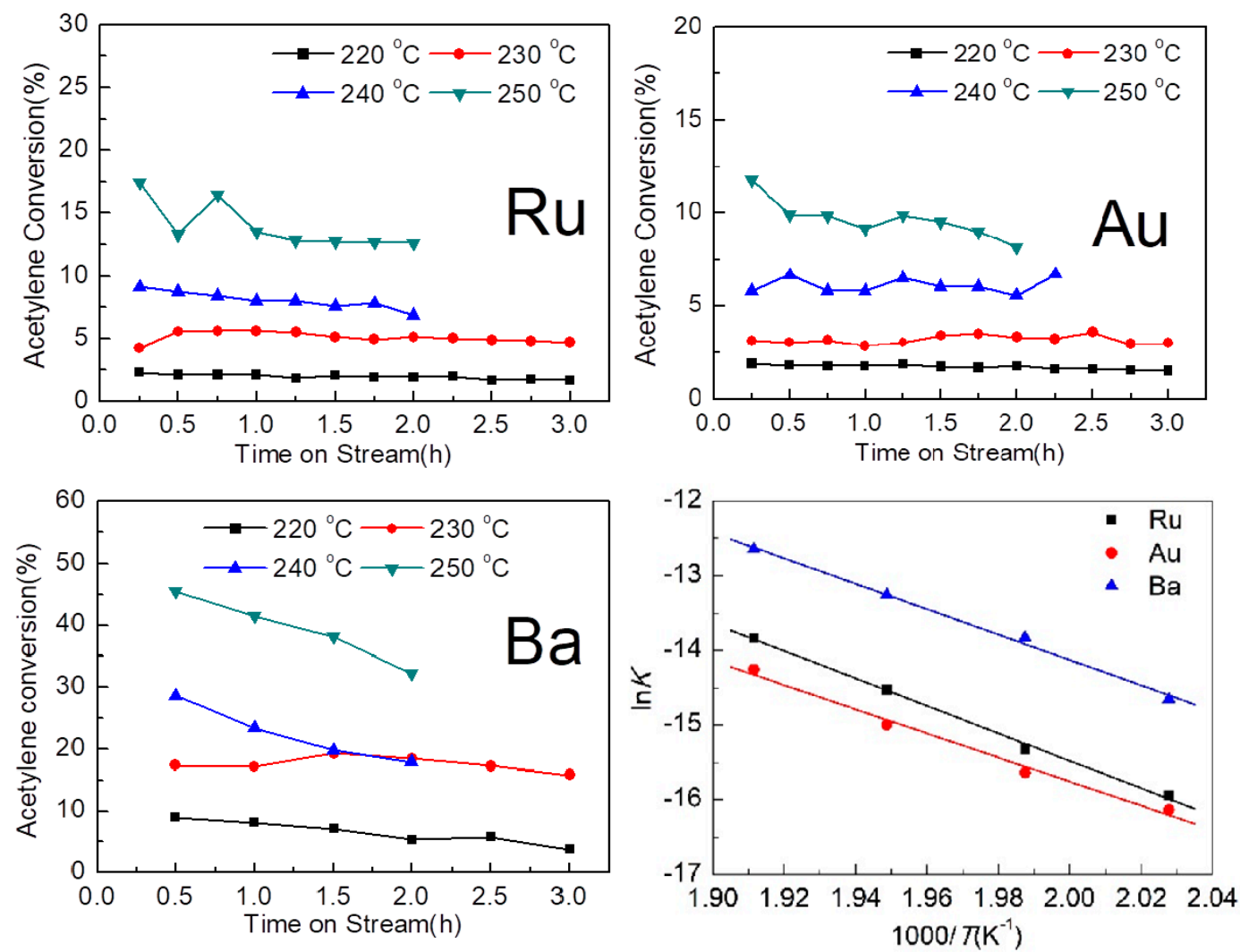

Figure 4. Experimental results of metal chloride catalysts for DCE-acetylene exchange reaction at 220, 230,240 and $250{ }^{\circ} \mathrm{C}$. Reaction conditions: GHSV $=90 \mathrm{~h}^{-1}, V\left(\mathrm{C}_{2} \mathrm{H}_{2}\right) / V(\mathrm{DCE})=1: 1.1$. The slope of linear fitting was used to determine the experimental activation energies according to the Arrhenius equation.

It can be seen that at a certain temperature, the $\ln K$ value of catalysts follows the sequence of $\mathrm{BaCl}_{2}>\mathrm{RuCl}_{3}>\mathrm{AuCl}_{3}$, which also indicates the same catalytic activity sequence. Besides, the experimental activation energies $\left(E_{\mathrm{a}}(\exp )\right)$ are also compared with the DFT calculation results $\left(\Delta G_{\mathrm{RDS}}\right)$ given in Table 2. The relative errors are less than $20 \%$ for all metal chlorides and the values among different metal catalysts are in the same sequence, which indicates great consistency between the experimental data and theoretical calculation. The successful prediction of catalytic activity can also be greatly helpful for the further design of catalysts for this reaction.

\subsection{Comparison with Acetylene Hydrochlorination Process}

Further energy analysis of acetylene hydrochlorination reaction was carried out to explain the reversed activity of metal chlorides for two reactions, as mentioned previously. Table S4 lists original energy values. Figure 5 shows the energy profiles and corresponding structures. $\mathrm{AuCl}_{3}$ and $\mathrm{RuCl}_{3}$ undergo a chlorine transfer pathway reported in previous study [23], in which one $\mathrm{Cl}$ atom is transferred from metal chloride to $\mathrm{C}_{2} \mathrm{H}_{2}$ molecule during the reaction. This pathway significantly reduces the energies of intermediates and facilitates the reaction, and the excellent chlorine transfer ability makes $\mathrm{AuCl}_{3}$ the ideal catalyst for this reaction $[23,24]$. However, the energy of IM2 in chlorine transfer pathway is so high $\left(-27.8 \mathrm{~kJ} \mathrm{~mol}^{-1}\right.$ for $\mathrm{BaCl}_{2}$ compared with -136.7 for $\mathrm{RuCl}_{3}$ and -167.7 for $\mathrm{AuCl}_{3}$ ) 
that the corresponding calculations do not give a converged structure of TS2, although $\mathrm{BaCl}_{2}$ still demonstrates the strongest adsorption of $\mathrm{C}_{2} \mathrm{H}_{2}$ in the first step (formation of Ads). Therefore, the chloride transfer pathway is not suitable for $\mathrm{BaCl}_{2}$, and a direct $\mathrm{C}_{2} \mathrm{H}_{2}$ and $\mathrm{HCl}$ combination pathway is adopted, which gives unique IM1 and TS1 species. The energy of transition state in rate-determining step has the sequence of $\mathrm{BaCl}_{2}<\mathrm{RuCl}_{3}<\mathrm{AuCl}_{3}$ and the activation energy is calculated to be 349.4, 158.5, and $122.3 \mathrm{~kJ} \mathrm{~mol}^{-1}$ for $\mathrm{BaCl}_{2}, \mathrm{RuCl}_{3}$, and $\mathrm{AuCl}_{3}$ respectively, due to the difference in chloride transfer ability. Therefore, the activity sequence $\mathrm{AuCl}_{3}>\mathrm{RuCl}_{3}>\mathrm{BaCl}_{2}$ for this reaction can be explained. This conclusion is crucial for catalyst design, because the screening criteria of metal chlorides for DCE-acetylene exchange reaction are significantly different from those for acetylene hydrochlorination reaction. Chlorides with higher adsorption energy of reactants are anticipated to be preferable for the previous reaction, while the chlorine transfer ability is important for the latter.

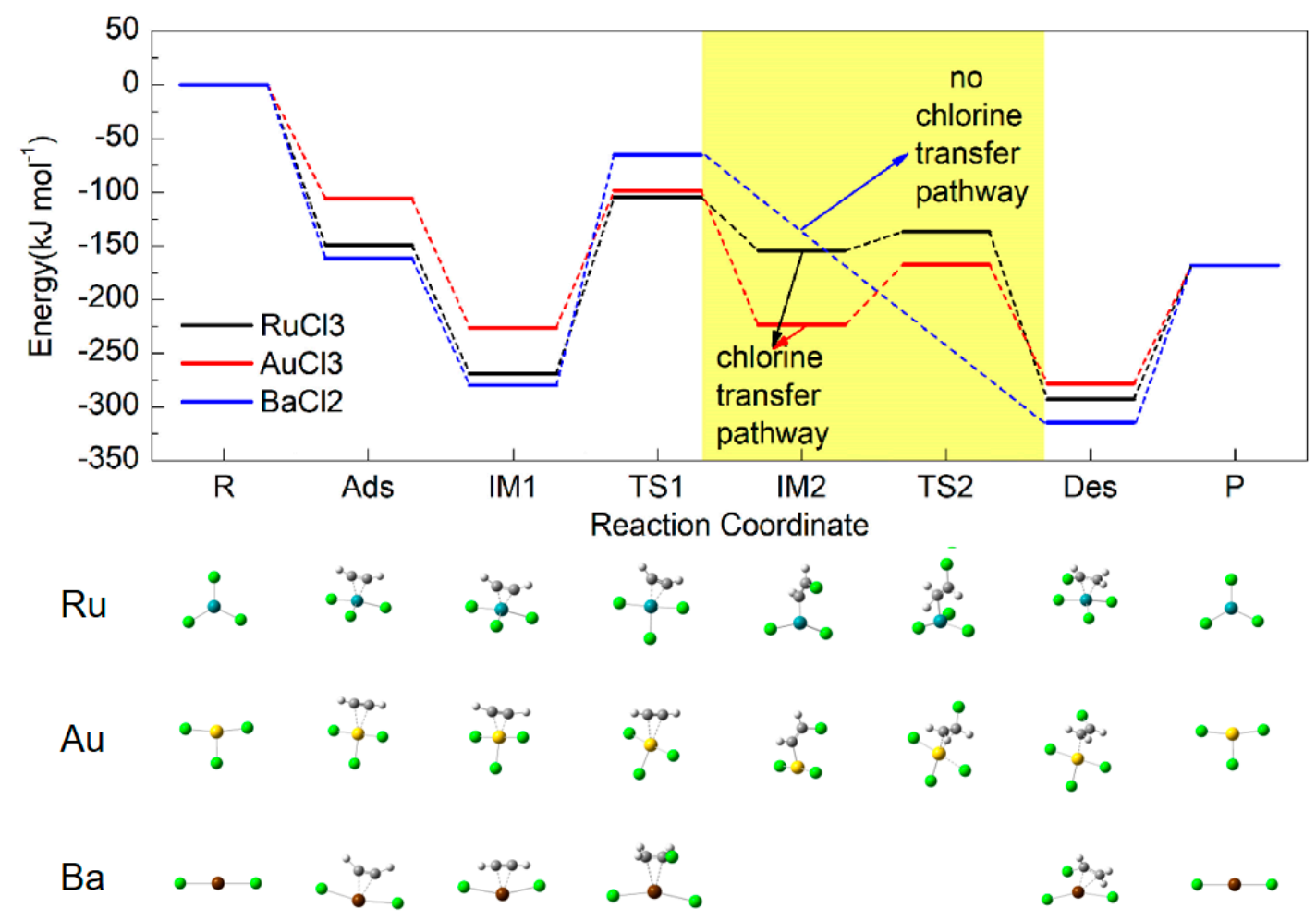

Figure 5. Energy profiles and corresponding structures of species for acetylene hydrochlorination reaction. Free molecules of $\mathrm{C}_{2} \mathrm{H}_{2}, \mathrm{HCl}$, and VCM are omitted for clarity.

\section{Calculation Methodology}

Gaussian 09 software (Gaussian, Inc., Wallingford, CT, USA) [25] was used in the entire calculation process. B3LYP functional, which is also widely used in relevant DFT studies, was selected to achieve the balance of accuracy and calculation expenses and produce data that can be easily compared with other published results. Therefore, B3LYP functional with default electron spin was used throughout the study [26]. Mixed electron basis set was adopted for calculation to make the best of calculation expenses. Specifically, light atoms, including $\mathrm{H}, \mathrm{C}$, and $\mathrm{Cl}$, were described by $6-31 \mathrm{~g}(\mathrm{~d})$ basis set and metal atoms were described by the Lanl2dz effective core potential (ECP) basis set. Energy minimum was achieved for all optimized structures, except transition states (TS), and the energy of TS was confirmed to be saddle point with one imaginary frequency.

Adsorption energies were used to quantify the adsorption strength of relevant species and defined, as in Equation (1):

$$
E_{\mathrm{Ads}}=E_{\mathrm{A}-\mathrm{C}}-E_{\mathrm{A}}-E_{\mathrm{C}}
$$


where $E_{\mathrm{Ads}}$ is the adsorption energy, $E_{\mathrm{A}-\mathrm{C}}$ is the energy of adsorbed species together with catalyst, $E_{\mathrm{A}}$ is the energy of free adsorbate, and $E_{C}$ is the energy of catalyst in its original form.

The energy of catalysts and reactants in original form was set to zero (symbol $\mathrm{R}$ in reaction coordinate) in the illustration of energy profiles in order to keep clarity. Subsequently, the energy of each species in reaction pathways was corrected by Equation (2):

$$
E_{\mathrm{S}}=E_{\mathrm{S} 0}-E_{\mathrm{C}}-E_{\mathrm{DCE}}-E_{\mathrm{C} 2 \mathrm{H} 2}
$$

where $E_{\mathrm{S}}$ is the corrected energy of species $S$ and it is shown in energy profiles, $E_{\mathrm{S} 0}$ is the original calculated energy of species $S$, and $E_{\mathrm{C}}, E_{\mathrm{DCE}}$, and $E_{\mathrm{C} 2 \mathrm{H} 2}$ refer to the energy of catalyst, 1,2-dichloroethane, acetylene in the original form, respectively.

The calculated activation energy $E_{a}$ was determined by the Gibbs free energy difference in the rate-determining step of corresponding reaction pathway, as shown in Equation (3):

$$
E_{a}=\Delta G_{\mathrm{RDS}}=\sum G_{\text {Product }}-\sum G_{\text {Reactant }}
$$

In Equation (3), the Gibbs free energy of each species was derived from thermal correction of electronic energies through frequency calculation. The typical temperature of $473.15 \mathrm{~K}\left(20{ }^{\circ} \mathrm{C}\right)$, which is most commonly used for this reaction, was applied throughout the calculation.

\section{Conclusions}

Two possible reaction pathways for DCE-acetylene exchange reaction, namely the DCE decomposition pathway and the acetylene-DCE complex pathway, were proposed and the second pathway was proved to be more favourable through adsorption energy calculation. The combination of $\mathrm{C}_{2} \mathrm{H}_{2}$ and $\mathrm{HCl}$ to form the second VCM molecule was proved to be the rate-determining step. An activity sequence of $\mathrm{BaCl}_{2}>\mathrm{RuCl}_{3}>\mathrm{AuCl}_{3}$ was predicted, and the activation energies were determined to be $189.1,141.4$, and $167.3 \mathrm{~kJ} \mathrm{~mol}^{-1}$ for $\mathrm{RuCl}_{3}, \mathrm{AuCl}_{3}$, and $\mathrm{BaCl}_{2}$ respectively. These calculation results were confirmed by experiments, and it is quite interesting that non-noble metals are more suitable than noble metals for this reaction, which can be an obvious cost advantage for practical applications. The different performances of the metal chlorides for two VCM producing reactions were successfully predicted and explained by revealing corresponding mechanisms, in which the adsorption ability is important for DCE-acetylene exchange reaction, while chloride transfer ability is important for acetylene hydrochlorination reaction. The results give instructions for catalyst design and preparation before the experimental study, which can accelerate the development of catalysts in the environmentally friendly new DCE route for VCM production.

Supplementary Materials: The following are available online at http://www.mdpi.com/2073-4344/10/2/204/s1, Figure S1: Structures of metal chlorides, (a) $\mathrm{RuCl}_{3}$, (b) $\mathrm{AuCl}_{3}$, (c) $\mathrm{BaCl}_{2}$. Unit of length and angle are $\AA$ and degree respectively, Figure S2: Optimized structure of adsorbed species on metal chloride surfaces, Figure S3: Catalytic turnover frequency of three metal chlorides for acetylene hydrochlorination reaction, Table S1: Main structure parameters of important species after adsorption. M stands for the metal atoms in metal chlorides. Bond length unit: $\AA$, angle unit: degree. Value in parentheses are corresponding values in free molecules, Table S2: Absolute energies in Hartrees of calculated species in DCE decomposition reaction pathway for DCE-acetylene exchange reaction, Table S3: Absolute energies in Hartrees of calculated species in acetylene-DCE complex reaction pathway for DCE-acetylene exchange reaction, Table S4: Absolute energies in Hartrees of calculated species for acetylene hydrochlorination reaction, Figure S4: Diagram of the experimental equipment (1) Controlling valve; (2) Rotor flowmeter; (3) Mass flowmeter; (4) Preheating furnace; (5) Reaction furnace; (6) Condenser; (7) Dryer; (8) Gas chromatography; (9) Exhausted gas absorption bottle; (10) High pressure liquid sampling pump, Figure S5: Reaction evaluation of $\mathrm{BaCl}_{2}$ catalysts with different catalyst loadings at constant GHSV. Reaction conditions: $T=220^{\circ} \mathrm{C}, \mathrm{GHSV}=90 \mathrm{~h}^{-1}, V\left(\mathrm{C}_{2} \mathrm{H}_{2}\right) / V(\mathrm{DCE})=1: 1.1$, Figure S6: Reaction evaluation of $\mathrm{BaCl}_{2}$ catalysts with different average sizes of support. Reaction conditions: $T=220^{\circ} \mathrm{C}, \mathrm{GHSV}=90 \mathrm{~h}^{-1}, V\left(\mathrm{C}_{2} \mathrm{H}_{2}\right) / V(\mathrm{DCE})=1: 1.1$, Figure S7: Reaction evaluation of $\mathrm{BaCl}_{2}$ catalysts with different $\mathrm{C}_{2} \mathrm{H}_{2}$ and DCE gaseous volume flux. Reaction conditions: $T=220^{\circ} \mathrm{C}$, Figure S8: Reaction evaluation of activated carbon support and reduced zero-valance metal catalysts. The reduction process was realized by treating prepared catalysts with sodium borohydride solution 
with excessive $\mathrm{NaBH}_{4}$ reduction capability. Reaction conditions: $T=260{ }^{\circ} \mathrm{C}, \mathrm{GHSV}=90 \mathrm{~h}^{-1}, V\left(\mathrm{C}_{2} \mathrm{H}_{2}\right) / V(\mathrm{DCE})=$ 1:1.1. The acetylene conversion was significantly lower than metal catalysts with high valances of metals.

Author Contributions: Experiment, H.X. and B.M.; DFT calculation, H.X.; writing-original draft preparation, H.X.; writing-review and editing, B.M.; supervision, G.L. All authors have read and agreed to the published version of the manuscript.

Funding: This work was funded by the National 863 Research Program of China (863 Program, 2012AA062901) and the State Key Research and Development Project (2016YFB0301603).

Conflicts of Interest: The authors declare no conflict of interest. The funders had no role in the design of the study; in the collection, analyses, or interpretation of data; in the writing of the manuscript, or in the decision to publish the results.

\section{References}

1. Liu, Z.; Yin, J.; Zhang, G.; Jin, W. The strategy of domestic PVC enterprise under new circumstance. Polyinyl Chloride 2015, 12, 43-44.

2. Li, G.; Zhou, J. The non-mercury trend of acetylene based PVC industry. China Chlor Alkali 2017, 3, 20-22.

3. Liu, G.; Ma, L.; Liu, J. Database Handbook of Physical Properties in Chemistry and Chemical Engineering; Chemical Industry Press: Beijing, China, 2002.

4. Dean, J.A. Handbook of Chemistry and Physics, 70th ed.; McGrawHill, Inc.: New York, NY, USA, 1990.

5. Wang, Y. The impact of mercury pollution on human health. Life Health 2004, 1, 21-23.

6. Selin, H. Global environmental law and treaty-making on hazardous substances: The minamata convention and mercury abatement. Glob. Environ. Politics 2014, 14, 1-19. [CrossRef]

7. Jiang, Z.; Wei, X.; Zhong, J. Jiang-Zhong new route for VCM production. Polyvinyl Chloride 2013, 41, 16-19.

8. Argaman, N.; Makov, G. Density functional theory: An introduction. Am. J. Phys. 2000, 68, 69. [CrossRef]

9. Jiang, Z.; Zhong, J.; Wei, X. Jiang-Zhong new VCM production process introduction and perspective. China Chlor Alkali 2014, 1, 24-26.

10. Zhao, W.; Li, W.; Zhang, J. Ru/N-AC catalyst to produce vinyl chloride from acetylene and 1,2-dichloroethane. Catal. Sci. Technol. 2016, 6, 1402-1409. [CrossRef]

11. Xu, H.; Zhou, K.; Si, J.; Li, C.; Luo, G. A ligand coordination approach for high reaction stability of an Au-Cu bimetallic carbon-based catalyst in the acetylene hydrochlorination process. Catal. Sci. Technol. 2016, 6, 1357-1366. [CrossRef]

12. Wan, F.; Chao, S.; Guan, Q.; Wang, G.-C.; Li, W. Reaction mechanisms of acetylene hydrochlorination catalyzed by $\mathrm{AuCl}$ 3/C catalysts: A density functional study. Catal. Comm. 2017, 101, 120-124. [CrossRef]

13. Han, Y.; Sun, M.; Li, W.; Zhang, J. Influence of chlorine coordination number on the catalytic mechanism of ruthenium chloride catalysts in the acetylene hydrochlorination reaction: A DFT study. Phys. Chem. Chem. Phys. 2015, 17, 7720-7730. [CrossRef] [PubMed]

14. Ma, J.; Shen, S.W.B. Study on the effects of acetylene on an $\mathrm{Au}-\mathrm{Cu} / \mathrm{C}$ catalyst for acetylene hydrochlorination using Monte Carlo and DFT methods. React. Kinet. Mech. Catal. 2013, 110, 177-186. [CrossRef]

15. Zhang, J.; He, Z.; Li, W.; Han, Y. Deactivation mechanism of $\mathrm{AuCl} 3$ catalyst in acetylene hydrochlorination reaction: A DFT study. RSC Adv. 2012, 2, 4814. [CrossRef]

16. Straub, B.F. Gold(I) or gold(III) as active species in $\mathrm{AuCl}(3)$-catalyzed cyclization/cycloaddition reactions? A DFT study. Chem. Commun. 2004, 1726-1728. [CrossRef]

17. Zhao, W.; Sun, M.; Zhang, H.; Dong, Y.; Li, X.; Li, W.; Zhang, J. Catalytic dehydrochlorination of 1,2-dichloroethane to produce vinyl chloride over N-doped coconut activated carbon. RSC Adv. 2015, 5, 104071-104078. [CrossRef]

18. Shen, Z.; Zhao, H.; Liu, Y.; Kan, Z.; Xing, P.; Zhong, J.; Jiang, B. Mercury-free nitrogen-doped activated carbon catalyst: An efficient catalyst for the catalytic coupling reaction of acetylene and ethylene dichloride to synthesize the vinyl chloride monomer. React. Chem. Eng. 2018, 3, 34-40. [CrossRef]

19. Hutchings, G.J. Vapor-phase hydrochlorination of acetylene-Correlation of catalytic activity of supported metal chloride catalysts. J. Catal. 1985, 96, 292-295. [CrossRef]

20. Hutchings, G.J. Catalysis: A golden future. Gold Bull. 1996, 29, 123-130. [CrossRef]

21. Hutchings, G.J. Nanocrystalline gold catalyst: A reflection on catalyst discovery and the nature of active sites. Gold Bull. 2009, 42, 8. [CrossRef] 
22. Zhou, K.; Jia, J.; Li, C.; Xu, H.; Zhou, J.; Luo, G.; Wei, F. A low content Au-based catalyst for hydrochlorination of $\mathrm{C} 2 \mathrm{H} 2$ and its industrial scale-up for future PVC processes. Green Chem. 2015, 17, 356-364. [CrossRef]

23. Conte, M.; Carley, A.F.; Heirene, C.; Willock, D.J.; Johnston, P.; Herzing, A.A.; Kiely, C.J.; Hutchings, G.J. Hydrochlorination of acetylene using a supported gold catalyst: A study of the reaction mechanism. J. Catal. 2007, 250, 231-239. [CrossRef]

24. Xu, H.; Meng, S.; Luo, G. Ionic liquids-coordinated Au catalysts for acetylene hydrochlorination: DFT approach towards reaction mechanism and adsorption energy. Catal. Sci. Technol. 2018, 8, 1176-1182. [CrossRef]

25. Frisch, M.; Trucks, G.W.; Schlegel, H.B.; Scuseria, G.E.; Robb, M.A.; Scalmani, G.; Barone, V.; Mennucci, B.; Petersson, G.A.; Nakatsuji, H.C.; et al. Gaussian 09; Gaussian Inc.: Wallingford, CT, USA, 2009.

26. Becke, A.D. A new mixing of Hartree-Fock and local density-functional theories. J. Chem. Phys. 1993, 98, 5648-5652. [CrossRef]

(C) 2020 by the authors. Licensee MDPI, Basel, Switzerland. This article is an open access article distributed under the terms and conditions of the Creative Commons Attribution (CC BY) license (http://creativecommons.org/licenses/by/4.0/). 